\title{
Analysis of Adipose-Derived Stem Cells from Different Donor Areas and Their Influence on Fibroblasts In Vitro
}

\author{
Xinhang Dong ${ }^{1}$ (1) $\cdot$ Mingzi Zhang ${ }^{2} \cdot$ Xiaolei Jin ${ }^{1}$
}

Received: 8 August 2021/Accepted: 11 August 2021/Published online: 23 August 2021

(C) Springer Science+Business Media, LLC, part of Springer Nature and International Society of Aesthetic Plastic Surgery 2021

Level of Evidence $V$ This journal requires that authors assign a level of evidence to each article. For a full description of these Evidence-Based Medicine ratings, please refer to the Table of Contents or the online Instructions to Authors www.springer.com/00266

Dear sir,

We have read the recent article by Dr. Antonio et al. [1] on assessing possible quantitative or qualitative differences in ADSCs derived from different donor subcutaneous adipose tissues. In this study, the authors concluded that the region of the dorsal upper back presented a greater number of ADSCs than the thighs, and no qualitative differences were observed between the ADSCs of the five areas analyzed. This experiment is meant for the determination of the preferential donor area. Here, we provide some thoughts on this study.

Firstly, Dr. Antonio et al. described that only VEGF correlates with fibroblastic migration. However, the relationship between VEGF and cell migration needs to be confirmed. Chemokines among different groups were not detected in this experiment, which are a group of cytokines in the body and play an important role in inducing cell migration $[2,3]$. There was confusion between the results and discussion about VEGF expression in the article, which was not discussed in detail. Furthermore, we would be very grateful if the authors could provide more detailed evaluation methods in Table 4.

Xiaolei Jin

professor.jin@yahoo.com

1 Plastic Surgery Hospital, Chinese Academy of Medical Sciences and Peking Union Medical College, Beijing, China

2 Department of Plastic Surgery, Peking Union Medical College Hospital, Chinese Academy of Medical Sciences and Peking Union Medical College, Beijing, China
Secondly, the experimental data obtained from the Human Premixed Multi-Analyte kit generally required further verification, which needs to be further supplemented [4].

Finally, Dr. Antonio et al. pointed out that supernatants of ADSCs from both the abdomen and thighs increased the rate of fibroblastic migration compared to that in the control group. We are also interested in further studies on the preferential donor area in liposuction.

\section{Declarations}

Conflict of interest The authors declare that they have no conflicts of interest to disclose.

Animal and Human Rights This article does not contain any studies with human participants or animals performed by any of the authors.

Informed Consent For this type of study, informed consent is not required.

\section{References}

1. Antonio G, Jayme A, Maristela D et al (2020) Analysis of adiposederived stem cells from different donor areas and their influence on fibroblasts in vitro. Aesth Plast Surg 44(3):971-978

2. Friedemann K, Arndt F (2011) The role of chemokines and their receptors in angiogenesis. Cell Mol Life Sci 68(17):2811-2830

3. Daniel F, Marcus T (2016) Chemokines: chemistry biochemistry and biological function. Chimia 70(12):856-859

4. Hao Y, Dong X, Zhang M (2020) Effects of hyperbaric oxygen therapy on the expression levels of the inflammatory factors interleukin-12p 40 , macrophage inflammatory protein- $1 \beta$, plateletderived growth factor-BB, and interleukin-1 receptor antagonist in keloids. Medicine 9(16):e19857

Publisher's Note Springer Nature remains neutral with regard to jurisdictional claims in published maps and institutional affiliations. 